Illinois State University

ISU ReD: Research and eData

Theses and Dissertations

4-1-2019

\title{
Unethical Pro-Organizational Behavior And Organizational Identification: Exploring The Moderating Effects Of Conscientiousness And Neuroticism
}

Conrad Niederhauser

Illinois State University, conradniederhauser@gmail.com

Follow this and additional works at: https://ir.library.illinoisstate.edu/etd

Part of the Psychology Commons

\section{Recommended Citation}

Niederhauser, Conrad, "Unethical Pro-Organizational Behavior And Organizational Identification: Exploring The Moderating Effects Of Conscientiousness And Neuroticism" (2019). Theses and Dissertations. 1087. https://ir.library.illinoisstate.edu/etd/1087

This Thesis is brought to you for free and open access by ISU ReD: Research and eData. It has been accepted for inclusion in Theses and Dissertations by an authorized administrator of ISU ReD: Research and eData. For more information, please contact ISUReD@ilstu.edu. 


\section{UNETHICAL PRO-ORGANIZATIONAL BEHAVIOR AND ORGANIZATIONAL IDENTIFICATION: EXPLORING THE MODERATING EFFECTS OF CONSCIENTIOUSNESS AND NEUROTICISM}

\section{CONRAD NIEDERHAUSER}

45 Pages

Little research in the field of industrial and organizational psychology has focused on unethical behavior intended to help the organizations and its members or the factors that may predict the prevalence of these behaviors. The purpose of this study was to further this research and examine possible moderating effects of conscientiousness and neuroticism on the relationship between organizational identification (OID) and unethical pro-organizational behavior (UPB). While no support was found to suggest higher levels of neuroticism or conscientiousness moderate the relationship between UPB and OID. This study contributed to the literature through investigating the role of individual-level differences on the OID to UPB relationship, as well as providing future directions for research through exploratory analyses.

KEYWORDS: unethical pro-organizational behavior, organizational identification, conscientiousness, neuroticism, personality 
UNETHICAL PRO-ORGANIZATIONAL BEHAVIOR AND ORGANIZATIONAL IDENTIFICATION: EXPLORING THE MODERATING EFFECTS OF CONSCIENTIOUSNESS AND NEUROTICISM

CONRAD NIEDERHAUSER

A Thesis Submitted in Partial Fulfillment of the Requirements for the Degree of

MASTER OF SCIENCE

Department of Psychology

ILLINOIS STATE UNIVERSITY 
(C) 2019 Conrad Niederhauser 
UNETHICAL PRO-ORGANIZATIONAL BEHAVIOR AND ORGANIZATIONAL IDENTIFICATION: EXPLORING THE MODERATING EFFECTS OF CONSCIENTIOUSNESS AND NEUROTICISM

CONRAD NIEDERHAUSER

COMMITTEE MEMBERS:

Dan Ispas, Chair

Alexandra Ilie 


\section{ACKNOWLEDGMENTS}

I would first like to express my sincere gratitude to my thesis chair Dr. Dan Ispas for his knowledge, patience, and guidance throughout the entire process of this master's thesis. I would also like to thank Dr. Alexandra Ilie and Dr. J Scott Jordan for their suggestions and feedback. Lastly, I would like to thank my friends and family who have supported and encouraged me throughout years of school and during the time of this study.

C.N. 


\section{CONTENTS}

Page

ACKNOWLEDGMENTS

CHAPTER I: INTRODUCTION AND RELATED LITERATURE 1

Unethical Pro-Organizational Behavior $\quad 1$

Organizational Identification and Unethical Pro-Organizational Behavior 5

Individual Differences as Moderators: Conscientiousness 6

Individual Differences as Moderators: Neuroticism $\quad 8$

$\begin{array}{ll}\text { Purpose } & 10\end{array}$

CHAPTER II: METHODS AND RESULTS 12

$\begin{array}{ll}\text { Method } & 12\end{array}$

$\begin{array}{lr}\text { Participants } & 12\end{array}$

$\begin{array}{ll}\text { Measures } & 13\end{array}$

$\begin{array}{ll}\text { Procedure } & 15\end{array}$

$\begin{array}{ll}\text { Results } & 16\end{array}$

$\begin{array}{ll}\text { Descriptive Statistics } & 16\end{array}$

$\begin{array}{ll}\text { Hypothesis Testing } & 16\end{array}$

$\begin{array}{ll}\text { Exploratory Analysis } & 17\end{array}$

CHAPTER III: DISCUSSION 22

General Discussion $\quad 22$

$\begin{array}{ll}\text { Practical Implications } & 23\end{array}$

$\begin{array}{ll}\text { Limitations } & 25\end{array}$

$\begin{array}{ll}\text { Future Research } & 27\end{array}$

$\begin{array}{lr}\text { REFERENCES } & 29\end{array}$ 
APPENDIX B - ORGANIZATIONAL IDENTIFICATION 34

$\begin{array}{ll}\text { APPENDIX C - CONSCIENTIOUSNESS } & 35\end{array}$

$\begin{array}{ll}\text { APPENDIX D - NEUROTICISM } & 37\end{array}$

APPENDIX E - MORAL DISENGAGEMENT 38

APPENDIX F - COUNTER-PRODUCTIVE WORK BEHAVIOR 40

APPENDIX G - DEMOGRAPHIC INFORMATION 41

APPENDIX H - ATTENTION CHECK QUESTIONS 42 


\section{CHAPTER I: INTRODUCTION AND RELATED LITERATURE}

Much research in the field of Industrial and Organizational Psychology has focused on counterproductive work behavior (CWB), which are the unethical actions of employees at work performed with the intention of harming the organization and/or its members, but comparatively little examines why employees commit unethical acts for the benefit of the organization. Research on the topic of unethical acts intended to aid the organization is more commonly referred to as unethical pro-organizational behavior (UPB). The potential for employees to commit unethical acts, even when they are intended to benefit the organization, can turn out to be rather costly in terms of legal fees, loss of business, and damage to reputation. Recent examples of this relatively unexplored phenomenon are Mitsubishi falsifying data on the quality of products used in the aerospace, automotive, and electric power industries, Uber's attempted cover-up of a data breach, Penn State's child sex abuse scandal, and the Volkswagen emissions scandal. Because of the importance of this issue and the key differences between UPB and other types of unethical behaviors at work, this study will aim to further explore this topic.

\section{Unethical Pro-Organizational Behavior}

Though the previously cited examples of UPB are all very high profile cases and very damaging, this need not be the case. UPB has been defined as "actions that are intended to promote the effective functioning of the organization or its members and violate core societal values, mores, laws, or standards of proper conduct." (Umphress \& Bingham, 2011, p. 622). This means that UPB can be as simple as a single employee falsely blaming contractors for 
shoddy work when interacting with customers or purposely exaggerating the effectiveness of a product in order to sell more.

To delineate further between counterproductive work behavior from unethical proorganizational behavior, CWB is "Behavior intended to have a detrimental effect on organizations and their members. It can include overt acts such as aggression and theft or more passive acts such as purposely failing to follow instructions or doing work incorrectly." (Fox \& Spector, 2001) while UPB is behavior enacted with the intention to aid the organization and its members (albeit through the unethical means). While these two constructs are similar conceptually, both are unethical behaviors that can include acts of omission and commission, the key difference between these two constructs is the intention with which the unethical behavior is enacted, as such, it would be reasonable to suspect different mechanisms may facilitate these behaviors enacted with opposing intentions.

Umphress, Bingham, and Mitchell (2010) first explored this area of research with a study introducing the concept of unethical pro-organizational behavior. This study examined the relationship between UPB and organizational identification, or the extent to which one identifies with an organization and internalizes the organization's successes and failures as their own (Mael \& Ashforth, 1992), as well as examining positive reciprocity beliefs as a moderator of that relationship. This theorized relationship posited that individuals with higher levels of organizational identification would be more likely to commit unethical acts of their own accord in order to aid the organization. Building on this, Umphress et al. also suggested that social exchange theory may play a role in this relationship. Their rationale being that social exchange theory proposes that a stronger relationship results from the back and forth exchange of resources between two parties, thus employees who hold the belief that there is a need to reciprocate 
exchange behaviors (positive reciprocity beliefs) would be more likely to commit UPB when they strongly identify with the organization. Umphress et al. (2010) did not find a statistically significant link between organizational identification and UPB alone (Study $1 \beta=.05, n s$, Study $2 \beta=.17, n s)$, however researchers did find that the interaction between organizational identification (OID) and positive reciprocity beliefs was positively linked to UPB (Study $1 \beta=$ $.17, p<.05$, Study $2 \beta=.15, p<.05)$, with higher levels of positive reciprocity beliefs being linked to a stronger relationship between OID and UPB (Study $1 \beta=.21, p<.05$, Study $2 \beta=$ $.26, p<.05$ ) and a nonsignificant relationship when positive reciprocity beliefs were low (Study $1 \beta=-.06, n s$, Study $2 \beta=-.01, n s$ ). However, a later study by Chen et al. (2016) found a significant direct relationship between OID and UPB (Study $1 B=1.38, p=.02$, Study $2 B=.23$, $p=.03$ ), as well as evidence to suggest that moral disengagement may partially mediate the relationship between OID and UPB (Study $1 B=.65, \mathrm{CI}=[.19,1.45]$, Study $2 B=.17, \mathrm{CI}=[.09$, .27]). Likewise, Kong (2016) found support for a positive relationship between OID and UPB ( $\beta$ $=.36, p<.01)$. These two studies providing evidence for a direct relationship between OID and UPB.

Much of UPB literature examines its attitudinal antecedents (Umphress et al., 2010, Chen, Chen, \& Sheldon, 2016, Matherne and Litchfield, 2012) but relatively little examines individual difference level factors (Kong, 2016, Castille, Buckner, \& Thoroughgood, 2016). In addition to the studies performed by Umphress et al. (2010) and Chen et al. (2016), Matherne and Litchfield (2012) examined moral identity and affective commitment as possible predictors of UPB, finding that both significantly predicted intention to commit UPB, with affective commitment being positively associated with UPB $(\beta=.197, p<.05)$ and moral identity negatively associated with UPB $(\beta=-.306, p<.001)$. Additionally, Matherne and Litchfield 
found support for their hypothesis that moral identity moderated the relationship between affective commitment and UPB $\left(\Delta R^{2}=.085, p<.001\right)$, such that those with high levels of moral identity experienced a weaker relationship between affective commitment and UPB. In a study involving ethical leadership and UPB, Miao, Newman, Yu, and Xu (2012) found a significant curvilinear relationship between the two. Similarly, a study by Effelsberg, Solga, and Gurt (2013) examined the relationship between transformational leadership, or an ability to transform a follower's perspective from being focused on their own goals to focusing on the goals of the group or organization, and the relationship between OID and UPB. Effelsberg et al. proposed that, given the goal-focused outcomes of transformational leadership shares much overlap with high levels of OID, transformational leadership (TFL) would lead to higher levels of OID and thus inadvertently lead to higher levels of UPB. Researchers found support for both hypotheses in their study, with higher levels of TFL being both positively related to employee willingness to engage in UPB (Study 1: $\mathrm{r}=0.12, p<0.05$; Study 2: $\mathrm{r}=0.12, p<.05$ ) and gave support to the hypothesis that OID mediates the relationship between OID and UPB.

While few studies have examined individual difference level factors, Kong (2016) is one example of a study that has. In this study, Kong analyzed how trait mindfulness and work passion affect willingness to engage in UPB. Trait mindfulness is a dispositional tendency to "be attentive to and aware of what is taking place in the present" (Brown \& Ryan, 2003, p. 822), while work passion is defined as "a strong inclination towards work that people like, that they find important, and in which they invest time and energy" (Vallerand et al., 2003, p.757). Work passion is then divided into the constructs of obsessive passion and harmonious passion. Obsessive passion is defined as "a controlled internalization of an activity in one's identity that creates and internal pressure to engage in an activity that the person likes" (Vallerand et al., 
2003, p.756) and harmonious passion is an "autonomous internalization that leads individuals to engage in the activity that the person likes" (Vallerand et al., 2003, p.756). Kong hypothesized that trait mindfulness could act as an inhibitory predictor of OID, that is to say the relationship between them would be negative. Kong found support for a negative relationship between trait mindfulness and UPB $(\beta=-.26, p<.01)$, as well as support for a positive relationship between obsessive passion and $\operatorname{OID}(\beta=.23, p<.01)$, though there was no significant relationship between harmonious passion and OID. Castille et al. (2016) also examined individual difference level factors in their study, specifically examining the relationship between trait Machiavellianism and willingness to engage in UPB, building on Kish-Gephart, Harrison, and Trevino (2010) which found Machiavellianism was a significant predictor of unethical behavior at work. Trait Machiavellianism is a tendency to ignore positive reciprocity norms, be interpersonally cold, and lack empathy (Castille et al., 2016). This hypothesis was supported, with researchers finding a positive relationship between trait Machiavellianism and willingness to engage in UPB $(\beta=.50, p<.001)$.

\section{Organizational Identification and Unethical Pro-Organizational Behavior}

One of the proposed antecedents of UPB is organizational identification (OID). As previously noted, Umphress et al. (2010), the study that first explored UPB, examined the relationship between UPB and organizational identification with positive reciprocity beliefs, in other words feelings of "obligations to return beneficial behavior to an organization with which they feel a strong membership" (Umphress et al., 2010, p. 770), as a moderator. Researchers found that individuals who more strongly identify with an organization are more likely to engage in UPB only when they have high positive reciprocity beliefs. Similar studies have found other factors influencing the OID/UPB relationship (Chen et al. 2016; Kong, 2016) such as work 
passion and trait mindfulness as moderators, as well as moral disengagement as a mediator, though little research has analyzed the OID/UPB relationship or the variables that facilitate it. As previously cited, several studies (Chen et al. 2016; Kong, 2015) have found a significant positive relationship between OID and UPB. Therefore, it is hypothesized that this study will find the same relationship.

Hypothesis 1: Organizational Identification will positively predict Unethical ProOrganizational Behavior.

\section{Individual Differences as Moderators: Conscientiousness}

Conscientiousness is defined as "dependability and volition and the typical behaviors associated with it include being hard-working, achievement-oriented, persevering, careful, and responsible" (Erdheim, Wang, \& Zickar, 2006, p. 961). Including conscientiousness as a moderator of the relationship between OID and UPB is rooted in the idea that as an employee identifies more with their organization, employees who are higher in conscientiousness will feel a stronger duty and obligation to help the organization. Previous studies note the importance of moral disengagement (sometimes referred to as neutralization) and how, as a result, employees are more likely to shift their viewpoint on committing unethical acts to help their organization (Chen et al. 2016; Umphress et al., 2010; Umphress \& Bingham, 2011), even viewing them as necessary or justified at higher levels of organizational identification. Moral disengagement, according to Chen et al. (2016), being "a set of cognitive justification mechanisms that allow an individual to commit unethical acts while disengaging from the moral norms and self-sanctions that ordinarily inhibit such acts." While no studies have explicitly explored the relationship 
between moral disengagement and conscientiousness, both Umphress et al. (2010) and Chen et al. (2016) found that moral disengagement increased the strength of the relationship between organizational identification and unethical pro-organizational behavior. This study posits that part of the reason for this could be that employees who are higher in conscientiousness may feel the obligation to help their organization, seeing it as a necessity, but are less likely to be dissuaded by 'moral norms' or 'self-sanctions' if moral disengagement has occurred. While no previous studies have examined the moderating effects of conscientiousness on the OID/UPB relationship, several studies provide indirect links that help to bolster the argument for it. First, Matherne and Litchfield (2012) found a link between affective commitment and UPB. This is notable, as Erdheim et al. (2006) found a strong link between affective commitment and conscientiousness. Together, these two studies show an indirect link from conscientiousness to UPB. Building on this, Kalshoven et al. (2011) found links between conscientiousness and ethical leadership. Tying this back to UPB and OID, Miao, Newman, Yu, \& Xu (2012) found a curvilinear relationship between ethical leadership and UPB. Meaning that employees who had moderately ethical leaders for the group that more highly identified with their supervisors were more likely to engage in UPB. This study helps illustrate the connection in several ways, first that (through Kalshoven et al., 2012) there is an indirect connection between conscientiousness and UPB via ethical leadership. Miao et al. also showed that the employees who identified more strongly with their supervisor, a concept that is conceptually similar to organizational identification, experienced this curvilinear relationship while employees who did not identify as strongly with supervisors did not. Fitting this into a person by situation framework, when moral disengagement has occurred and an employee feels a high degree of identification with the organization, those with higher levels of conscientiousness, and thus having a tendency to be 
guided by obligation and to be dependable, may be more prone to engage in behaviors that would fulfill perceived obligations to the organization. Even when that means committing unethical acts to fulfil that obligation. Conversely, when levels of organizational identification are lower and moral disengagement has not occurred, those with higher levels of conscientiousness are not expected to engage in greater amounts of UPB.

Hypothesis 2: The positive relationship between OID and UPB is stronger when conscientiousness levels are high versus low.

\section{Individual Differences as Moderators: Neuroticism}

Erdheim et al. (2006, p. 960) defines neuroticism as "Individual differences in the tendency to experience distress. Typical behaviors associated with this factor include being anxious, depressed, angry, embarrassed, emotional, worried, and insecure.” Similar to the rationale behind examining conscientiousness as a possible moderator of the OID/UPB relationship, the theory behind including neuroticism as a moderator is that as one identifies more with the organization and moral disengagement occurs, employees who are high in neuroticism will be more willing to engage in unethical acts in order to help the organization circumvent perceived threats. The rationale being that individuals who are high in neuroticism will perceive threats to the organization as greater and be more concerned with them and as a result of high levels of organizational identification may feel obligated to defend the organization against perceived threats. Again, there are indirect links connecting neuroticism with the OID/UPB relationship. For instance, Stephan et al. (2009) have linked obsessive passion with trait neuroticism. Additionally, Kong (2015) found significant relationships between obsessive passion (a type of work passion) and OID as well as between obsessive passion and UPB. 
Meaning that neuroticism has been previously been tied to obsessive passion, which in turn has been tied to both UPB and OID. Another indirect link is established by Walumbwa \& Schaubroeck (2009), which found a link between emotional stability (a reversed version of neuroticism) with ethical leadership. As previously mentioned Miao et al. (2012) found a curvilinear relationship between ethical leadership and UPB when levels of identification with a supervisor were high. Again, this provides evidence of indirect links between neuroticism and ethical leadership as well as between neuroticism and identification with a supervisor. Fitting this into a person by situation framework, when moral disengagement has occurred and an employee feels a high degree of identification with the organization, those with higher levels of neuroticism, and thus are prone to feel more insecure and worried, may also be more prone to engage in behaviors that would protect the organization they identify with. Placed in a situation where the organization they identify with may be adversely affected, those with high levels of neuroticism may become more concerned than others and thus feel more pressure to act unethically. Conversely, when levels of organizational identification are lower and moral disengagement has not occurred, those with higher levels of neuroticism are not expected to engage in greater amounts of UPB.

Hypothesis 3: The positive relationship between OID and UPB is stronger when neuroticism levels are high versus low.

While none of these studies provides a clear and direct link between the proposed moderators and the direct OID/UPB relationship, they are evidence of indirect relationships between the proposed moderators and the variables of interest. Although no direct relationships were cited here, very little research has examined individual-level differences as moderators on 
the OID/UPB relationship. Despite a lack of direct evidence that these variables would affect the strength of the relationship, the indirect relationships cited do still help to bolster the argument that neuroticism and conscientiousness may moderate the relationship between organizational identification and unethical pro-organizational behavior, as they effectively illustrate that there are statistically significant relationships between the variables of interest as well as with constructs of a similar nature. Also, as previously mentioned, examining these variables in the context of a person by situation framework also helps to establish why these personality variables are likely to moderate the relationship between OID and UPB. These individual level differences may interact with situational factors to produce differing outcomes. In this case, the argument is that those faced with a situation in which they can help an organization they strongly identify with by doing something unethical are more likely to do so if they have higher levels of trait conscientiousness and/or trait neuroticism.

\section{Purpose}

The purpose of this study is to further examine the relationship between organizational identification and unethical pro-organizational behavior as well as to further explore the possible effects of individual differences on the relationship between organizational identification and unethical pro-organizational behavior. Specifically, this study focuses on the possible effects of conscientiousness and neuroticism on the relationship between OID and UPB, as well as whether or not these traits might strengthen the observed relationship. The expected effects of conscientiousness and neuroticism both are that individuals who are higher in these personality traits will experience a stronger relationship between organizational identification and unethical 
pro-organizational behavior, whereas those low in trait neuroticism and low in trait conscientiousness will not experience a stronger relationship between these two variables. 


\section{CHAPTER II: METHODS AND RESULTS}

\section{Method}

\section{Participants}

The sample for this research study was gathered using the Amazon Mechanical Turk program. Participants in this study were restricted to adults who have been employed fulltime (35 or more hours per week) for a minimum of three months. Participants were also asked to report information about their occupation, which was used to ensure that they have opportunities to engage in OID and UPB.

The total sample consisted of 741 adults, though 307 were removed due to various constraints, leaving a sample of 434 for this study. Means, standard deviations, and correlations for all scales are included in Table 1. Participants who did not complete and submit the survey were removed from the analysis. This resulted in the removal of 117 cases. Additionally, the data for this study was screened to ensure participants were not minors, had a job tenure of 3 months or longer, reported working 35 or more hours per week, and had only taken the survey once. This resulted in the removal of an additional 101 cases. A further 90 cases were removed for failing any of the attention checks included in this study, due to concerns that participants may have answered randomly, made use of test-taking programs, or that they simply provided low quality data through lack of attentiveness and/or engagement. These attention checks each constituted an extremely simple question or instructions that any adult would expected to answer correctly (e.g. "For this question please select neither agree nor disagree"). Participants in this sample worked an average of 42.38 hours per week in the United States, had an average job

tenure of 7.81 years, and had an average age of 41.12 years. A total of $37.6 \%$ of respondents 
reported that they were managers and $62.4 \%$ of the sample reported working directly with customers. 228 of the participants were female, 205 were male, and one participant was another gender or chose not to identify. $73.8 \%$ of participants had attained a college degree (including those with some graduate work or a graduate degree). Participants in this sample were also largely employed elsewhere, with 430 employed full-time outside of MTurk.

\section{Measures}

Unethical pro-organizational behavior. To measure UPB, this study used a 6-item selfreport scale adapted from Umphress, Bingham, and Mitchell (2010). The only change being that items asked participants to report previous incidence of UPB they committed rather than intentions to commit UPB. Items assessed participants' reported incidence of committing UPB on a 5-point Likert scale, with responses ranging from Never (1) to Every day (5) regarding how often they have engaged in related behaviors. Umphress et al. (2010) found their implementation of this scale had a coefficient alpha of 0.89 and, through EFA that these 6 items loaded onto a single factor that accounted for $66.9 \%$ of the variance. Other studies have generally favorable reliability coefficients for this scale, reporting values ranging from 0.68 to 0.97 , with an average of 0.85 (Miao et al., 2013; Graham, Ziegert, \& Capitano, 2015; Kong, 2016; Castille, et al., 2015; Effelsberg \& Solga, 2015; Lee et al., 2015). In the current study, this scale had a coefficient alpha of .82 .

Organizational identification. This study used Mael and Ashforth's (1992) 6-item selfreport scale to assess OID. Items assessed participants' level of organizational identification on a 5-point Likert scale, with responses ranging from Strongly Disagree (1) to Strongly Agree (5) regarding how much each item sounds like their own behavior. Mael and Ashforth (1992) found this scale had a coefficient alpha of 0.87 . Other studies have generally favorable reliability 
coefficients for this scale, reporting values ranging from 0.81 to 0.92 , with an average of 0.82 (Umphress et al., 2010; Chen et al., 2016; Kong, 2016; Effelsberg \& Solga, 2015; Lee et al., 2015). In the current study, the coefficient alpha for this scale was .89 .

Conscientiousness. In order to assess participants' levels of conscientiousness, this study incorporates 3 of the subscales from The Chernyshenko Conscientiousness Scale (Chernyskenko, 2002). This study specifically used the facets of virtue $(\alpha=.81)$, industriousness $(\alpha=.86)$, and responsibility $(\alpha=.72)$ (Green, O'Connor, Gartland, \& Roberts, 2015). This resulted in the measure being a 30-item scale. Items assessed participants' reported levels of conscientiousness on a 4-point Likert scale, with responses ranging from Strongly Disagree (1) to Strongly Agree (4) regarding the extent to which items resemble their behavior. In the current study, the overall scale had a coefficient alpha of .92 .

Neuroticism. In order to assess participants' levels of neuroticism, this study incorporates 4 of the subscales from Goldberg et al. (2006). This scale is available on the International Personality Item Pool. This study specifically used the facets of anxiety $(\alpha=.83)$, vulnerability ( $\alpha=.82)$, immoderation $(\alpha=.77)$, and self-consciousness $(\alpha=.80)$ (Goldberg et al. 2006). This resulted in the measure being a 40 -item scale. Items assessed participants' reported levels of neuroticism on a 5-point Likert scale, with responses ranging from Strongly Disagree (1) to Strongly Agree (5) regarding the extent to which items resemble their behavior. In the current study, the overall scale had a coefficient alpha of .94 .

Moral disengagement. In order to assess participants' levels of moral disengagement, this study made use of the Propensity to Morally Disengage Scale (Moore et al., 2012). Specifically, this study used the 16-item version of the scale. Items assessed participants' levels of moral disengagement on a 7-point Likert scale ranging from Strongly Disagree (1) to Strongly 
Agree (7). Moore et al. (2012) found this scale had a coefficient alpha of 0.88. In the current study, this scale had a coefficient alpha of .90 .

Counterproductive work behavior. In order to assess participants' levels of counterproductive work behavior, this study made use of the 10-item CWB-C scale (Spector, Bauer, \& Fox, 2010). Items assessed participants' levels of CWB on a 5-point Likert scale ranging from Never (1) to Every Day (5). Spector et al. (2010) found coefficient alphas of .78 and .89. In the current study, this scale also had a coefficient alpha of .83 .

\section{Procedure}

The measures for this study were completed via MTurk and Qualtrics. Previous research has shown that MTurk is an appropriate alternative to more traditional methods of collecting data (Behrend, Sharek, Meade, \& Wiebe, 2011). Participants were paid $\$ 0.50$ for taking the survey.

Specifically, participants were recruited on MTurk where they provided with a link to the survey, which was hosted on Qualtrics. Once they opened the link to the survey, they were asked to read an informed consent form. Given the sensitive nature of some of the items in this study, participants were assured of their anonymity before the survey was administered and asked not to take the survey at work. After reading the informed consent form, participants proceeded through the 121-item survey. After completing the survey, participants received a randomly generated code that they were asked to submit on MTurk in order to receive payment. 


\section{Results}

\section{Descriptive Statistics}

This study performed all confirmatory analyses on the remaining 434 cases, analyses were performed on the dataset having only removed only duplicate responses and all findings for the hypotheses tested in this study were the same. The full dataset is available upon request. The average score on the measure of UPB for this study was rather low $(M=8.46, S D=3.42, n$ $=433)$, as was the average score on the measure of $(\mathrm{CWB} M=16.25, S D=5.44, n=432)$. Both

of these results are, however, concurrent with previous findings, which suggest that there is a low base rate for these behaviors.

\section{Hypothesis Testing}

Hypothesis 1 - OID and UPB. The first hypothesis of this study was that OID $(M=$ 20.81, $S D=6.11, n=434)$ would positively predict UPB $(M=8.46, S D=3.42, n=433)$. In order to test this hypothesis, a bivariate correlational analysis was conducted, which did not support a relationship between OID and UPB, $r(431)=.08, p=.11$ (see Table 1). Table 1 lists correlations between all measures below.

Hypothesis 2 - conscientiousness moderates OID and UPB. The second hypothesis of this study was that the relationship between OID and UPB would be stronger when conscientiousness levels are high versus low. This was tested by conducting a hierarchical regression with OID and conscientiousness $(M=97.13, S D=13.70, n=423)$ entered as predictors in the first step, followed by inputting an interaction term (calculated by multiplying participants' OID scores and conscientiousness scores) in the second step. Conscientiousness 
was not found to moderate the relationship between OID and UPB, $\Delta R^{2}=.002, F(3,418)=1.12$, $p=.29$. The full results of this analysis can be found below in Table 2 .

Hypothesis 3 - neuroticism moderates OID and UPB. The third and final hypothesis of this study was that the relationship between OID and UPB would be stronger when neuroticism levels are high versus low. This hypothesis was tested by conducting a hierarchical regression with OID and neuroticism $(M=103.04, S D=26.56, n=426)$ entered as predictors in the first step and inputting an interaction term (calculated by multiplying participants' OID scores and neuroticism scores) in the second step. Neuroticism was not found to moderate the relationship between OID and UPB, $\Delta R^{2}<.001, F(3,422)=.11, p=.74$. The full results of this analysis can be found below in Table 3 .

\section{Exploratory Analysis}

As previously mentioned, the hypotheses were tested without removing participants due to failing any of the attention checks, failed to answer their age, failed to answer how many hours they worked, worked less than 35 hours per week, did not report their job tenure, or had a job tenure of less than 3 months. These analyses followed the same procedures listed for hypotheses 1 through 3 . None of the three hypotheses were supported by this expanded dataset nor were they supported by the confirmatory dataset used in the hypothesis testing section.

In further examining the data, some interesting patterns emerged. One such finding was obtained by restricting participants to those who had indicated that they work directly with customers. Amongst this group, a significant relationship between OID and UPB was observed after conducting a bivariate correlation analysis, $r(269)=.15, p=.01$. However, further analysis did not support hypothesis 2 or hypothesis 3 within this subgroup (using the same methodology 
detailed in the hypothesis testing section). Following this, a variable was calculated by adding participant responses on the UPB scale including only the questions that did not directly reference "customers". Following this, hypotheses 1 through 3 were tested using this adjusted measure of UPB as the outcome variable. OID was found to significantly predict this adjusted measure of UPB, $r(432)=.10, p=.03$. However, when testing hypotheses 2 and 3 with this adjusted outcome variable, conscientiousness was not found to moderate the relationship with OID, $\Delta R^{2}=.003, F(3,419)=1.2, p=.27$, nor was neuroticism found to moderate this relationship, $\Delta R^{2}=.001, F(3,422)=.29, p=.59$.

Additionally, one assumption of this study was that those who are employed at an organization for longer would have higher organizational identification. Support was found for this claim, as it was discovered in the bivariate correlation analysis that there was a significant positive correlation between the two, $r(432)=.13, p<.01$. Managerial status was not significantly correlated with UPB, $r(433)=-.05, p=.26$. Also of note, CWB was significantly correlated with UPB, $r(431)=.38, p<.001$. Table 1 provides the correlations between all scales used in this study.

In examining the relationships between the predictors of interest in this study with CWB, it appears that CWB correlates with OID, $r(431)=-.25, p<.001$, conscientiousness, $r(431)=-$ $.49, p<.001$, as well as neuroticism, $r(431)=.35, p<.001$. As a result, further analysis was conducted to examine whether the relationships hypothesized about in this study might be supported with CWB as an outcome rather than UPB. A regression analysis conducted with OID as the predictor variable and CWB as the outcome variable was found to be statistically significant with participant levels of OID negatively predicting levels of CWB, $R^{2}=.25, F(430$, $1)=.251, p<.001$. Following this, another regression was conducted with OID and 
conscientiousness in the first model and with the conscientiousness and OID interaction term included in the next model. However, the interaction model was not significant, $\Delta R^{2}<.01, F(3$, $417)=1.11, p=.29$. Likewise, a regression was conducted with neuroticism and OID as the predictor variables in the first model and the neuroticism and OID interaction term in the second. As with the previous interactive model, this was found to be non-significant, $\Delta R^{2}<.001, F(3$, $420)=.86, p=.36$. In further analyzing the correlations between conscientiousness with both UPB and CWB, it was found that there was a significant difference between these correlations, $t(431)=4.05, p<.001$. Similarly, in analyzing the correlations between neuroticism and both UPB and CWB, it was found that there was a significant difference between these correlations, $t(423)=-4.11, p<.001$. Which suggests that these are significantly more predictive of CWB than of UPB. The correlations between OID with both UPB and CWB were also analyzed. Specifically, the correlation between OID and the modified scale of UPB, which included only items referencing customers, was compared to the correlation between OID and CWB. This analysis revealed a significant difference between correlations, $t(433)=6.83, p<.001$, which suggests that OID is significantly more predictive of CWB rather than UPB (at least concerning this scale).

Lastly, correlations between the subfacets of neuroticism and the subfacets of conscientiousness with OID and UPB were examined. For neuroticism, no facets were significantly correlated with OID. While the overall scale of neuroticism in this study was significantly correlated with UPB, not all subfacets of neuroticism were. Specifically, vulnerability and immoderation were found to correlate with UPB, $r(429)=.13, p<.01$ and $r(430)=.18, p<.001$ respectively, while anxiety and self-consciousness were not significantly correlated with UPB, $r(431)=.08, p=.10$ and $r(432)=.09, p=.06$. Just as the overall scale of 
conscientiousness was correlated with both OID and UPB, the subfacets of conscientiousness were all significantly related to both UPB and OID. Industriousness was significantly correlated to UPB, $r(430)=-.22, p<.001$, and OID, $r(431)=.37, p<.001$. Responsibility was significantly correlated to UPB, $r(429)=-.25, p<.001$, and OID, $r(430)=.30, p<.001$. Virtue was significantly correlated to UPB, $r(428)=-.31, p<.001$, and OID, $r(429)=.30, p<.001$. Following this, subfacets were used in place of broader personality traits to assess is some of the facets of trait might moderate the relationship between OID and UPB. This was first done in the overall sample and later in the sample who worked directly with customers in their role. Within the overall sample, neither immoderation nor vulnerability were found to moderate the relationship between OID and UPB, $\Delta R^{2}=.001, F(3,426)=.35, p=.56$ and $\Delta R^{2}<.001, F(3$, $425)=.17, p=.69$ respectively. Likewise, within the sample that only included participants who worked directly with customers no evidence of moderation was found for either immoderation or vulnerability, $\Delta R^{2}=.002, F(3,265)=.46, p=.50$ and $\Delta R^{2}=.002, F(3,263)=.56, p=.46$ respectively. Within the overall sample, the subfacets of conscientiousness were also not found to moderate the relationship between OID and UPB, $\Delta R^{2}<.05, F(3,426)=2.61, p=.11$ (industriousness), $\Delta R^{2}<.001, F(3,424)=1.22, p=.27$ (virtue), and $\Delta R^{2}<.002, F(3,425)=.50$, $p=.48$ (responsibility). Likewise, within the customer interaction sample the subfacets of conscientiousness were not found to moderate the relationship between OID and UPB, $\Delta R^{2}<$ $.05, F(3,265)=.01, p=.94$ (industriousness), $\Delta R^{2}<.002, F(3,264)=.52, p=.47$ (virtue), and $\Delta R^{2}=.001, F(3,265)=.17, p=.68$ (responsibility).

Moral disengagement was also examined as a possible moderator of the OID to UPB relationship. Within the overall sample, moral disengagement was not found to moderate this relationship, $\Delta R^{2}=.001, F(3,427)=.58, p=.45$. Nor was moral disengagement found to 
moderate the relationship between OID and UPB within the sample of participants who directly interacted with customers, $\Delta R^{2}=.003, F(3,266)=.83, p=.36$. 


\section{CHAPTER III: DISCUSSION}

\section{General Discussion}

The purpose of the current study was to investigate the relationship between OID and $\mathrm{UPB}$, as well as to examine the possible effects of conscientiousness and neuroticism on that relationship. None of the three hypotheses tested in this study were supported. Contrary to much of the previous research in this area, this study found a lack of support for the direct relationship between OID and UPB. This may be due to the nature of the UPB scale developed by Umphress, Bingham, and Mitchell (2010), which seems to include some items that may not apply to jobs that do not directly involve working with customers. As mentioned in the exploratory analysis section, participants who indicated working directly with customers were found to experience a significant direct relationship between OID and UPB, such that hypothesis 1 would have been satisfied.

Additionally, as no support was found for hypothesis 2 or hypothesis 3 (even when restricting the dataset to participants who work directly with customers) it would seem unlikely that these factors moderate the relationship between OID and UPB. In spite of this, both conscientiousness and neuroticism were found to be significantly correlated with UPB, $r(422)=$ $.30, p<.001$ and $r(425)=.14, p<.01$ respectively. This does provide some evidence that these individual-level difference factors are related to UPB. Future research should further examine the role of these factors and other individual-difference level factors on the incidence of UPB. Further, the relationship between moral disengagement and conscientiousness was significant, $r(421)=-.68, p<.001$. Contrary to what was hypothesized in this paper, it may be the case that instead of facilitating the relationship between conscientiousness and UPB, that 
conscientiousness may act as a buffer to engaging in moral disengagement in the first place. Future research might examine this relationship in greater detail.

A further issue of interest was the disambiguation between CWB and UPB. While there was a significant correlation between CWB and UPB, this correlation was not disturbingly high at $r=.38$. As such, it would seem to suggest that there is some overlap between CWB and UPB, but that they remain distinct constructs. However, it is also important to keep in mind that this study only compares a single 10-item measure of CWB with a scale of reported incidence of committing UPB. Further research on the relationship between CWB and UPB would certainly better elucidate the differences between the differences between these constructs.

Additionally, while the subfacets of conscientiousness and the overall scale of conscientiousness showed similar relationships with OID and UPB, the same was not true of neuroticism. The subfacets of anxiety and self-consciousness did not significantly relate to UPB, whereas immoderation and vulnerability did. This too runs counter to counter to the proposed rationale for how neuroticism could moderate a relationship between OID and UPB.

Specifically, it shows a lack foundation for the idea that as a person experiences higher levels of OID, if they are concerned about the well-being of the organization that they would be more likely to commit acts of UPB. Instead, the data collected in this sample would seem to show that those who engage in UPB are more prone to erratic or impulsive behavior.

\section{Practical Implications}

Based on the exploratory finding that those working directly with customers experienced a relationship between OID and UPB, but those who did not work directly with customers did not, it is possible this scale is more applicable to jobs where employees work directly with 
customers. This may be a result of the way several of the items are worded, as many specifically reference a "customer" or "client". If employees do not work directly with customers, this may mean that they still engage in types of UPB, but that these would go unreported as these items may not apply to them (regardless of their willingness to engage or past incidence of engaging in other types of UPB). Further evidence of this possible effect was found by removing all questions that reference customers from the UPB scale, as OID was found to predict this adjusted measure of UPB in all participants. As a result, organizations looking to examine levels of UPB should consider that the unaltered scale might underreport incidence of UPB amongst those who do not work directly with customers.

Additionally, the correlations between conscientiousness and UPB as well as neuroticism and UPB could all be of practical use for organizations. If used in the selection process, selecting for higher levels of conscientiousness and lower levels of neuroticism could lessen the potential for employees to engage in UPB in the workplace. Additionally, by examining levels of conscientiousness and neuroticism amongst current employees, organizations might determine who is at a greater risk for committing UPB and provide targeted interventions in order to lessen the likelihood of these employees committing UPB. If the incidence of UPB in the workplace can be reduced through either selection or targeted interventions, it could help organizations avoid the costly outcomes associated with UPB such as legal disputes and related damage to the public face of the organization. Additionally, as lower levels of conscientiousness and higher levels of neuroticism were also associated with CWB in this study, selecting for high conscientiousness and low neuroticism or staging interventions on this basis could also help in reducing the incidence of $\mathrm{CWB}$ in the workplace, which likewise has its own costly and negative outcomes associated with it. 
While restricting the sample to include only participants who reported working directly with customers revealed a significant relationship between OID and UPB, CWB was also found to be negatively correlated with OID. This suggests that OID can lead to beneficial and harmful outcomes in different circumstances. Organizations should continue to encourage the development of OID in employees; however, they should also be aware of the increased likelihood of UPB and account for this through training and making employees aware of the importance of adhering to legal and ethical standards, regardless of potential benefits to the organization.

\section{Limitations}

While this study attempted to employ best practice, there were a few notable limitations in this study. First, this study employed a cross-sectional design. While the use of a crosssectional design is convenient (and more cost effective than alternatives), it does limit the conclusions that can be drawn. Namely, as this study was observational in nature, it is questionable to what extent any of these variables were truly predictive of the outcomes of interest. As such, future studies should consider making use of a longitudinal design rather than cross-sectional, to better establish the predictive nature of these relationships or the lack thereof.

Another limitation of this study was the reliance on self-report data. While this is common practice and, by far, a more efficient method of measuring UPB than direct observation, it is still vulnerable to biased responding. In addition to the threat of social desirability, some of the measures in this study specifically ask about illegal and/or unethical behaviors. While participants were cautioned not to take the study at work and were assured of their anonymity, it is certainly possible that participants may have been concerned about reporting past incidence of 
behaviors that are considered unethical and are sometimes illegal and thus chosen not to report them or to underreport them.

Further, this study relied on a self-report sample from Amazon's Mechanical Turk. While the author went to great lengths to remove any cases that did not fit the criteria for analysis or multiple cases that appeared to be from the same participant. As a result, this study removed a large number of participants from the dataset for a variety of reasons. While this was done before data analysis and with the intention of pursuing best practices and being more conservative with regards to the potential inclusion of duplicate cases, it might be the case that participants employed a VPN or other method of spoofing their location and retook the study using separate accounts. Likewise, it is potentially possible that some of the participants may have been "bots"; or rather, that someone may have created a program to input fake responses in order to obtain a reward for participation. This study is no more likely to be have been affected by these issues than any other study that makes use of a sample sourced online, though it is potentially possible that it may have affected the results. Future studies might consider examining these relationships with samples in alternate settings in order to ensure that these issues have not affected the results reported in this study.

Lastly, this study made use of a revised version of Umphress et al.'s (2010) measure of UPB. The measure included in this study asks participants to rate the frequency with which they have engaged in UPB, rather than their willingness to engage in hypothetical UPB. While the difference does seem small, this paired with possible concerns participants may have had with regards to self-reporting unethical and/or illegal actions might have lessened reported UPB scores. Additionally, though the differences between these scales are unlikely to be noteworthy, 
it would be beneficial for future research to ensure this by comparing this revised scale of UPB incidence with Umphress et al.'s (2010) original scale of intention to commit UPB.

\section{Future Research}

Needless to say, the results of this study were surprising. All 3 hypotheses were not supported. This does, however, raise many questions and create directions for future research.

While this study's first hypothesis, that OID would predict UPB, was not supported, it was found through exploratory analysis that this hinged on whether or not participants worked directly with customers. Further analysis showed that removing these items that reference customers from the measure of UPB produced a significant relationship between OID and UPB in the full sample. Additionally, many of the items on the Umphress et al. (2010) measure of UPB specifically mention "customers or clients". This study also made use of a measure of UPB that asked participants about frequency of behavior rather than willingness to engage in UPB. This, paired with past studies supporting a relationship between OID and UPB, suggests that it may be the case that participants in this study felt that they did not have the opportunity to engage in these types of UPB and thus answered that they had not engaged in UPB. However, if they had been asked about their willingness to undertake such behaviors or had they been presented with items more germane to their working conditions, it is possible hypothesis 1 may have been supported. First, further studies should attempt to confirm that the difference in the OID to UPB relationship differs on the basis of participants working directly with customers. Should this prove to be the case, future research should then attempt to better disentangle opportunity to engage in UPB from willingness to commit it and incidence of having engaged in UPB. Specifically, future research should consider further developing scales of UPB to circumvent this issue, either by creating a scale with more generally applicable items or 
rewording items to be better aligned with particular job contexts and testing them with groups of participants who work in specific conditions.

As previously mentioned, much of the research examining UPB does so using crosssectional designs; future research should also endeavor to explore other frameworks that would allow for data collection at multiple points in time. Doing so would better illustrate if higher levels of OID could actually predict higher incidence of UPB.

While they do not seem to moderate the relationship between OID and UPB, this study found that both conscientiousness and neuroticism do correlate with UPB. Future research should examine the role these and other individual difference level factors play in predicting UPB. As both conscientiousness and neuroticism were found to be significantly correlated with UPB, future research might examine if other personality variables can be used to predict UPB. Little research has examined individual difference level factors, and while this study did not find support for its hypotheses, the significant correlations between the personality variables examined and UPB suggest they may be useful in further exploration of predictors of UPB and may be used to predict UPB on their own.

As previously mentioned, the relationship between moral disengagement and conscientiousness was also significant. While it was considered that moral disengagement might facilitate those with higher levels of conscientiousness and higher levels of OID engaging in more UPB, this strong negative correlation and the failure to support hypothesis 2 suggest that it may instead be the case that higher levels of conscientiousness can buffer against the development of moral disengagement in the first place. Future studies should attempt to explore the relationship between conscientiousness and moral disengagement, specifically to examine circumstances where obligation to an organization conflicts with moral or ethical obligations. 


\section{REFERENCES}

Barrick, M. R., \& Mount, M. K. (1991). The big five personality dimensions and job performance: A Meta-Analysis. Personnel Psychology, 1-26.

Behrend, T. S., Sharek, D. J., Meade, A. W., \& Wiebe E. N. (2011). The Viability of Crowdsourcing for Survey Research. Behavior Research Methods, 800-813.

Brown, K. W. \& Ryan, R. M. (2003). The Benefits of Being in the Present: Mindfulness and its Role in Psychological Well-being. Journal of Personality and Social Psychology, 84, $822-848$.

Castille, C. M., Buckner, J. E., \& Thoroughgood, C. N. (2016). Prosocial Citizens Without a Moral Compass? Examining the Relationship Between Machiavellianism and Unethical Pro-Organizational Behavior. Journal of Business Ethics, 1-12.

Chen, M., Chen, C. C., \&; Sheldon, O. J. (2016). Relaxing moral reasoning to win: How organizational identification relates to unethical pro-organizational behavior. Journal of Applied Psychology, 101(8), 1082-1096.

Chernyshenko, OS. Unpublished doctoral dissertation. University of Illinois; UrbanaChampaign: 2002. Applications of ideal point approaches to scale construction and scoring in personality measurement: The development of a six-faceted measure of conscientiousness.

Effelsberg, D. \&; Solga, M. (2015). Transformational leaders' in-group versus out-group orientation: Testing the Link between leaders' organizational identifcation, their willingness to engage in unethical pro-organizational behavior, and follower perceived transformational leadership. Journal of Business Ethics, 126(4), 581-590. 
Effelsberg, D., Solga, M., \&; Gurt, J. (2014). Transformational leadership and follower's unethical behavior for the benefit of the company: A two-study investigation. Journal of Business Ethics, 81-93.

Erdheim, S., Wang, M. \& Zickar M. J. (2006). Linking the Big Five Personality Constructs to Organizational Commitment. Personality and Individual Differences, 41, 959-970.

Fox, J. \& Miles, D. (2006). Counterproductive Work Behavior (CWB) in Response to Job Stressors and Organizational Justice: Some Mediator and Moderator Tests for Autonomy and Emotions. Journal of Vocational Behavior, 59, 291-309.

Goldberg, L. R., Johnson, J. A., Eber, H. W., Hogan, R., Ashton, M. C., Cloninger, C. R., \& Gough, H. C. (2006). The International Personality Item Pool and the future of publicdomain personality measures. Journal of Research in Personality, 40, 84-96.

Graham, K. A., Ziegert, J. C., \&amp; Capitano, J. (2015). The effect of leadership style, framing, and promotion regulatory focus on unethical pro-organizational behavior. Journal of Business Ethics, 126(3), 423-436.

Green, J. A., O'Connor, D. B., Gartland, N., \& Roberts, B. W. (2015). The Chernyshenko Conscientiousness Scales: A new facet measure of conscientiousness. Assessment.

Kalshoven, K., van Dijk, H., \&; Boon, C. (2016). Why and when does ethical leadership evoke unethical follower behavior? Journal of Managerial Psychology, 31(2), 500-515.

Kish-Gephart, J. J., Harrison, D. A., \& Trevino, L. K. (2010). Bad Apples, Bad Cases, and Bad Barrels: Meta-Analytic Evidence About Sources of Unethical Decisions at Work. Journal of Applied Psychology, 95(1), 1-31. 
Kong, D. T. (2016). The pathway to unethical pro-organizational behavior. Personality and Individual Differences, 93, 86-91.

Mael, F., \& Ashforth, B. E. (1992). Alumni and Their Alma Mater: A Partial Test of the Reformulated Model of Organizational Identification. Journal of Organizational Behavior, 13, 103-124.

Matherne, C. F., \& Litchfield S. R. (2012). Investigating the Relationship Between Affective Commitment and Unethical Pro-Organizational Behaviors: The Role of Moral Identity. Journal of Leadership, Accountability, and Ethics. 9(5), 35-46.

McCrae, R. R., \& John, O. P. (1992). An introduction to the five-factor model and its applications. Journal of Personality, 2, 175-215.

Miao, Q., Newman, A., Yu, J., \&; Xu, L. (2013). The relationship between ethical leadership and unethical pro-organizational behavior: Linear or curvilinear effects? Journal of Business Ethics, 641-653.

Moore, C., Detert, J. R., Treviño, L. K., Baker, V. L., \& Mayer, D. M. (2012). Why employees do bad things: Moral disengagement and unethical organizational behavior. Personnel Psychology, 65, 1-48.

Spector, P. E., Bauer, J. A., \& Fox, S. (2010). Measurement artifacts in the assessment of counterproductive work behavior and organizational citizenship behavior: Do we know what we think we know? Journal of Applied Psychology, 95(4), 781-790.

Umphress, E. E., \&; Bingham, J. B. (2011). When Employees Do Bad Things for Good Reasons: Examining Unethical Pro-Organizational Behaviors. Organization Science, 11, 621-640. 
Umphress, E. E., Mitchell, M. S., \&; Bingham, J. B. (2010). Unethical Behavior in the Name of The Company the Moderating effect of Organizational Identification and Positive Reciprocity Beliefs on Unethical Pro-Organizational Behavior, Journal of Applied Psychology, 95(4), 769-780.

Vallerand, R.J., Blanchard, C., Mageau, G.A., Koestner, R., Ratelle, C., Léonard, M., ... Marsolais, J. (2003). Les passions de l'âme: On Obsessive and Harmonious Passion. Journal of Personality and Social Psychology, 85, 756-767.

Walumbwa, F. O., \& Schaubroeck, J. (2009). Leader Personality Traits and Employee Voice Behavior: Mediating of Ethical Leadership and Work Group Psychological Safety, Journal of Applied Psychology, 94(5), 1275-1285. 


\section{APPENDIX A - UNETHICAL PRO-ORGANIZATIONAL BEHAVIOR}

Instructions: The following statements represent behaviors you may have performed at work. For each statement, please rate how often you engage in these behaviors.

\begin{tabular}{||ccccc||}
\hline 1 & 2 & 3 & 4 & 5 \\
Never & Once or twice & Once or twice per month & Once or twice per week & Every day \\
\hline
\end{tabular}

1. Because it was needed, I have concealed information

from the public that could be damaging to my organization

$\begin{array}{llll}2 & 3 & 4 & 5\end{array}$

2. B ecause our organization needed me to, I have

withheld is suing a refund to a customer or client accidentally overcharged .........

3. B ecause it helped my organization, I have exaggerated the truth about my company's products or services to cus tomers and clients

4. B ecause it benefited my organization, I have with held negative

information about my company or its products from customers andclients ........

5. B ecause it helped my organization, I have misrepresented the

truth to make my organization look good.

1

6. B ecause my organization needed me to, I have given a good

recommendation on the behalf of an incompetent employee in the hope that the

pers on would become another organization's problem instead of my own .........

$\begin{array}{lllll}1 & 2 & 3 & 4 & 5\end{array}$

$\begin{array}{lllll}1 & 2 & 3 & 4 & 5\end{array}$

$\begin{array}{lllll}1 & 2 & 3 & 4 & 5\end{array}$

$\begin{array}{lll}3 & 4 & 5\end{array}$

$\begin{array}{lllll}1 & 2 & 3 & 4 & 5\end{array}$ 


\section{APPENDIX B - ORGANIZATIONAL IDENTIFICATION}

[ 1 =Strongly disagree; 5 =Strongly agree $]$

Please indicate your level of agreement/disagreement with the following statements.

1 When someone criticizes my organization, it feels like a personal insult.

$2 \mathrm{I}$ am very interested in what others think about my organization.

3 When I talk about my organization, I usually say 'we' rather than 'they'.

4 My organization's successes are my successes.

5 When someone praises my organization, it feels like a personal compliment.

6 If a story in the media criticized my organization, I would feel embarrassed. 


\section{APPENDIX C - CONSCIENTIOUSNESS}

Please indicate your level of agreement/disagreement with the following statements.

[ 1 =Strongly disagree; 4 =Strongly agree]

I have high standards and work toward them.

I go above and beyond of what is required.

(R) I do not work as hard as the majority of people around me.

(R) I invest little effort into my work.

I demand the highest quality in everything I do.

I try to be the best at anything I do.

I make every effort to do more than what is expected of me.

(R) I do what is required, but rarely anything more.

(R) Setting goals and achieving them is not very important to me.

(R) Getting average grades is enough for me.

I carry out my obligations to the best of my ability.

I often feel responsible for making sure that all group project assignments are completed.

I go out of my way to keep my promises.

(R) Sometimes it is too much of a bother to do exactly what is promised.

I would gladly spend some of my leisure time trying to improve my community.

(R) If I am running late to an appointment, I may decide not to go at all.

(R) I am usually not the most responsible group member, but I will not shirk on my duties either.

If I am running late, I try to call ahead to notify those who are waiting for me.

(R) When I make mistakes I often blame others.

(R) I have a reputation for being late for almost every meeting or event. 
(R) If I could get away with it, I would not pay taxes.

(R) I would lie without hesitation if it serves my purpose.

(R) I could be insincere and dishonest if the situation required me to do so.

(R) If I find money laying around, I'll keep it to myself.

If a cashier forgot to charge me for an item I would tell him/her.

I would rather get a bad grade than copy someone else's homework and turn it in as my own.

It bothers me when people cheat on their taxes.

If I accidentally scratched a parked car, I would try to find the owner to pay for the repairs.

I firmly believe that under no circumstances it is okay to lie.

The people who know me best would say that I am honest. 


\section{APPENDIX D - NEUROTICISM}

Each item is rated on a 5-point Likert scale from $1=$ Strongly Disagree to $5=$ Strongly Agree

Please indicate your level of agreement/disagreement with the following statements.

+ keyed Worry about things.

Fear for the worst.

Am afraid of many things.

Get stressed out easily.

Get caught up in my problems.

- keyed Am not easily bothered by things.

Am relaxed most of the time.

Am not easily disturbed by events.

Don't worry about things that have already happened.

Adapt easily to new situations.

+ keyed Panic easily.

Become overwhelmed by events.

Feel that I'm unable to deal with things.

Can't make up my mind.

Get overwhelmed by emotions.

- keyed Remain calm under pressure.

Can handle complex problems.

Know how to cope.

Readily overcome setbacks.

Am calm even in tense situations.

+ keyed Often eat too much.

Don't know why I do some of the things I do.

Do things I later regret.

Go on binges.

Love to eat.

- keyed Rarely overindulge.

Easily resist temptations.

Am able to control my cravings.

Never spend more than I can afford.

Never splurge.

+ keyed Am easily intimidated.

Am afraid that I will do the wrong thing.

Find it difficult to approach others.

Am afraid to draw attention to myself.

Only feel comfortable with friends.

Stumble over my words.

- keyed Am not embarrassed easily.

Am comfortable in unfamiliar situations.

Am not bothered by difficult social situations.

Am able to stand up for myself. 


\section{APPENDIX E - MORAL DISENGAGEMENT}

Propensity to Morally Disengage Scale

Please indicate your level of agreement/disagreement with the following statements.

Each item is rated on a 7-point Likert scale from $1=$ Strongly Disagree to 7 = Strongly Agree

Moral Justification

It is okay to spread rumors to defend those you care about.*

It is alright to lie to keep your friends out of trouble.*

Playing dirty is sometimes necessary in order to achieve noble ends.

Euphemistic Labelling

Taking something without the owner's permission is okay as long as

you're just borrowing it.*

It's okay to gloss over certain facts to make your point.*

When you're negotiating for something you want, not telling the whole

story is just part of the game.

Advantageous Comparison

Considering the ways people grossly misrepresent themselves, it's

hardly a sin to inflate your own credentials a bit.*

Compared to other illegal things people do, taking something small from

a store without paying for it isn't worth worrying about.*

Damaging property is no big deal when you consider that others are

assaulting people.

Displacement of Responsibility

People shouldn't be held accountable for doing questionable things when they were just doing what an authority figure told them to do.*

People cannot be blamed for misbehaving if their friends pressured them

to do it.*

You can't blame people for breaking the rules if that's what they were taught to do by their leaders. 
Diffusion of Responsibility

People can't be blamed for doing things that are technically wrong when all their friends are doing it too.*

It's okay to tell a lie if the group agrees that it's the best way to handle the situation.*

In contexts where everyone cheats, there's no reason not to.

Distortion of Consequences

Taking personal credit for ideas that were not your own is no big deal.*

Walking away from a store with some extra change doesn't cause any harm.*

It is OK to tell small lies when negotiating because no one gets hurt.

Dehumanization

Some people have to be treated roughly because they lack feelings that can be hurt.*

It's okay to treat badly somebody who behaves like scum.*

Violent criminals don't deserve to be treated like normal human

beings.

Attribution of Blame

People who get mistreated have usually done something to bring it on themselves.*

If a business makes a billing mistake in your favor, it's okay not to tell them about it because it was their fault.*

If people have their privacy violated, it's probably because they have not taken adequate precautions to protect it.

Items measured on a 7-point Likert scale ranging from strongly disagree to strongly agree.

Items in bold comprise the final 8-item measure. Items marked with * comprise the 16-item measure. 


\section{APPENDIX F - COUNTER-PRODUCTIVE WORK BEHAVIOR}

10-Item Short Version of the Counterproductive Work Behavior Checklist (CWB-C)

\begin{tabular}{|c|c|c|c|c|c|}
\hline $\begin{array}{l}\text { How often have you done each of the following things on your } \\
\text { present job? }\end{array}$ & $\sum_{\bar{d}}^{\bar{d}}$ & 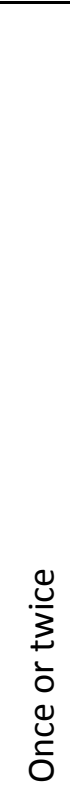 & 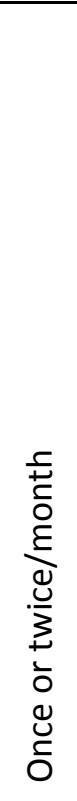 & 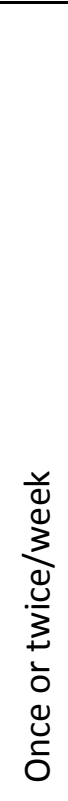 & $\begin{array}{l}\text { ते } \\
\frac{\pi}{0} \\
\frac{\lambda}{d} \\
\end{array}$ \\
\hline 1. Purposely wasted your employer's materials/supplies & 1 & 2 & 3 & 4 & 5 \\
\hline 2. Complained about insignificant things at work & 1 & 2 & 3 & 4 & 5 \\
\hline 3. Told people outside the job what a lousy place you work for & 1 & 2 & 3 & 4 & 5 \\
\hline 4. Came to work late without permission & 1 & 2 & 3 & 4 & 5 \\
\hline 5. Stayed home from work and said you were sick when you weren't & 1 & 2 & 3 & 4 & 5 \\
\hline 6. Insulted someone about their job performance & 1 & 2 & 3 & 4 & 5 \\
\hline 7. Made fun of someone's personal life & 1 & 2 & 3 & 4 & 5 \\
\hline 8. Ignored someone at work & 1 & 2 & 3 & 4 & 5 \\
\hline 9. Started an argument with someone at work & 1 & 2 & 3 & 4 & 5 \\
\hline 10. Insulted or made fun of someone at work & 1 & 2 & 3 & 4 & 5 \\
\hline
\end{tabular}




\section{APPENDIX G - DEMOGRAPHIC INFORMATION}

Gender:

Male

Female

Other

Age

What is your highest level of education? college Some high school or less Graduated high school Graduated College

- What is your current employment status?

- I am currently employed outside M-Turk.

- I am currently unemployed outside M-Turk, but have had past jobs other than M-Turk.

- I have never been employed outside M-Turk

- If you are currently unemployed outside M-Turk, please skip the following questions:

- How many hours do you currently work per week?

- What is the job title that you currently hold?

- How long have you worked in your current job? Years Months

- Do you currently hold a managerial position? (Yes/No)

- In your current role do you work directly with customers? 


\section{APPENDIX H - ATTENTION CHECK QUESTIONS}

(interspersed throughout survey)

- For this response, please select the fourth answer. (included in OID questions, random order through Qualtrics)
- Strongly Disagree
- Somewhat Disagree
- Neither Agree nor Disagree
- Somewhat Agree
- Strongly Agree

- Please choose the correct answer to the following question: $1+1=$ (included in Conscientiousness scale, random order through Qualtrics)
○ 1
○ 0
○ 2
○ 15

- The Sun rises in the west (included in Neuroticism scale, random order through Qualtrics)
- Strongly Disagree
- Somewhat Disagree
- Neither Agree nor Disagree
- Somewhat Agree
- Strongly Agree

- For this response, please select Neither Agree nor Disagree.(included in Moral Disengagement scale, random order through Qualtrics)
- Strongly Disagree
- Disagree
- Somewhat Disagree
- Neither Agree nor Disagree
- Somewhat Agree
- Agree
- Strongly Agree 
Table 1

Correlations, means, and standard deviations among all study measures $(N=434)$. Cronbach alpha estimates are displayed in parentheses along the diagonal.

\begin{tabular}{|c|c|c|c|c|c|c|}
\hline Measure & 1 & 2 & 3 & 4 & 5 & 6 \\
\hline OID & $(.89)$ & & & & & \\
\hline Conscientiousness & $.36 * * *$ & $(.92)$ & & & & \\
\hline Neuroticism & -.08 & $-.45 * * *$ & $(.94)$ & & & \\
\hline UPB & -.08 & $-.30 * * *$ & $.14 * *$ & $(.82)$ & & \\
\hline CWB & $-.25 * * *$ & $-.49 * * *$ & $.35 * * *$ & $.38 * * *$ & $(.83)$ & \\
\hline Moral Disengagement & $-.16 * *$ & $-.68 * * *$ & $.32 * * *$ & $.31 * * *$ & $.40 * * *$ & $(.90)$ \\
\hline$M$ & 20.81 & 97.13 & 103.04 & 8.50 & 16.25 & 38.31 \\
\hline$S D$ & 6.11 & 13.70 & 26.56 & 3.42 & 5.44 & 14.69 \\
\hline$N$ & 433 & 434 & 423 & 426 & 432 & 432 \\
\hline
\end{tabular}

Note. OID Organizational Identification; UPB = Unethical Pro-Organizational Behavior; $\mathrm{CWB}=$ Counterproductive Work Behavior.

$* p<.05 ; * * p<.01 ; * * * p<.001$. 
Table 2

Additive and interactive models of Organizational Identification and Conscientiousness

predicting Unethical Pro-Organizational Behavior $(N=422)$.

\begin{tabular}{llllll}
\hline Model & Predictor & $B$ & $S E B$ & $\beta$ & $\Delta R^{2}$ \\
\hline 1 & OID & .02 & .03 & .04 & $.09^{* * *}$ \\
& Conscientiousness & $-.08^{*}$ & .01 & -.31 & \\
& OID & .22 & .19 & .39 & .002 \\
& Conscientiousness & -.03 & .04 & -.14 & \\
& OID x & -.002 & .002 & -.45 & \\
& Conscientiousness & & & & \\
& OID Organizational & &
\end{tabular}

Note. $\quad$ OID $=$ Organizational Identification.

$* p<.05 ; * * p<.01 ; * * * p<.001$. 
Table 3

Additive and interactive models of Organizational Identification and Neuroticism predicting Unethical Pro-Organizational Behavior $(N=425)$.

\begin{tabular}{llllll}
\hline Model & Predictor & $B$ & $S E B$ & $\beta$ & $\Delta R^{2}$ \\
\hline 1 & OID & -.03 & .03 & -.05 & $.02 * *$ \\
& Neuroticism & $-.02 * *$ & .01 & .14 & \\
& OID & .01 & .10 & .01 & .000 \\
& Neuroticism & .02 & .01 & .19 & \\
& OID x & .000 & .001 & -.08 & \\
Neuroticism & & & & \\
Note. & OID = Organizational Identification. & & \\
$* p .05, * * p<.01$. & & & &
\end{tabular}

